\title{
International technology transfer and innovative changes adjustment in EU
}

\author{
Robert W. Ciborowski ${ }^{1}$ (D) Iwona Skrodzka ${ }^{1}$ \\ Received: 10 October 2017 / Accepted: 18 March 2019 / Published online: 1 April 2019 \\ (c) The Author(s) 2019
}

\begin{abstract}
The purpose of the paper is to analyse the role of international technology transfer (as part of an economic system) in the processes of creating and applying innovation, as well as the impact of technology on the efficiency of economic activity conducted by business entities. The study encompasses the economic activity of European Union countries and the companies functioning in the framework of national economic systems. The analysis was conducted by means of the soft modelling method. This method enabled to examine links between variables which are not directly observable in particular between international technology transfer and innovation. The results demonstrate that for countries relying on international technology transfer, being part of an economic system does have a positive impact on innovation. Thanks to international cooperation, companies (and countries in general) become more involved in innovation activity, which enhances their competitive position.
\end{abstract}

Keywords International technology transfer · Innovation · European Union countries $\cdot$ Soft modelling method

JEL Classification $\mathrm{C} 31 \cdot \mathrm{C} 38 \cdot \mathrm{O} 30 \cdot \mathrm{O} 33$

\section{Introduction}

Enterprises which implement active strategies of technological development have the greatest significance for the economy and ensure better conditions for the transformation of obtained technologies into new products or processes. The accumulation of technological capacities is the main aspect of the technological convergence of less

\footnotetext{
$\bowtie \quad$ Iwona Skrodzka

i.skrodzka@uwb.edu.pl

Robert W. Ciborowski

r.ciborowski@uwb.edu.pl

1 Faculty of Economics and Management, University of Bialystok, Białystok, Poland
} 
developed countries. The role of the state in this process has ceased to be a crucial one (see Audretsch et al. 2012, pp. 306-309).

Enterprises are hindered by numerous "negative external effects", or negative nonprice factors (lack of appropriate suppliers, unpredictability of the law, limited sources of financing, technical infrastructure). Individual companies must compensate for these shortages by establishing relations (cooperation) with other firms (see Radosevic 1999, p. 125; Belderbos et al. 2013, pp. 6-9).

Compensatory efforts allowing to restrict negative factors happen through creating network relationships (conglomerates, clusters), undertaking various forms of foreign cooperation (joint ventures, alliances), or better exploitation of existing relationships of a financial or infrastructural nature. In European countries, for instance, processes of this kind occur extremely rarely, and enterprises typically use internal capacities for development (ownership-based cooperation between companies). Meanwhile, in Asian countries, the processes of compensation are more intensive (see Stark 1996, p. 996; De La Tour et al. 2011).

The purpose of the paper is to analyse the role of international technology transfer (as a part of economic system) in the process of creation and application of innovation, as well as the impact of technology on the efficiency of economic activity conducted by the business entities. The study encompasses the economic activity of European Union countries and the companies functioning in the framework of national economic systems.

The paper consists of seven sections. Section 2 discusses the theoretical aspects of technological transfer. Subsequently, a description of the method used in the research is presented (soft modelling). Section 4 contains a specification of the soft model. Sections 5 and 6 are devoted to a discussion of the results. The paper closes with a conclusions.

\section{Determinants and consequences of technological flows}

The pace of technological convergence is associated with the intensity with which new knowledge is sought by domestic companies and the intensity with which capital for new technologies adopted from abroad is gained, i.e. international technology transfer (ITT). In this case, ITT relies on the rate at which new solutions are adopted by technology-seeking enterprises (see Saggi 2002; Maskus 2004).

There are several paths for ITT and access to technological capital. First, there is foreign direct investment (FDI), which makes it possible to reach new technologies and use the existing models of their implementation or application (see Ozawa 1992, pp. 27-54). The key benefits of this approach include changing the character of production into a more complex one and development of higher-technology sectors. Second, through international cooperation, companies increase their R\&D expenditure, thus boosting the technological intensity and technical advancement of their production (see Hobday 1995, pp. 72-80). Third, international links allow enterprises to broaden the scope of application of new technologies onto a higher number of branches or sectors. In the long term, accumulation of resources and possibilities in less technologically developed branches prompts companies to search for new, more innovative forms or 
scopes of activities from processing to R\&D (see Gu and Steinmueller 1996, pp. 2-3; Daim et al. 2014, pp. 32-44).

This type of processes must go closely together with the development of human resources (knowledge, experience, skills, cooperation), because of their inevitable complementarity and the tendency towards greater share of $R \& D$ in entrepreneurial activity. Further steps towards higher levels of technological development require better efficiency at adopting new solutions.

From the standpoint of international technology transfer, it should be pointed out that a decisive rise in international knowledge flows has been observed. This is caused by the development of technologies related to information transfer, telecommunication, television, Internet, the emergence of a knowledge-based economy, whose eminent feature is an international character of the created innovations, as well as by greater use of technology transfer channels. Moreover, the necessity to dynamise economic development has increased the demand for human capital, thereby encouraging the improvement of educational and science systems. It is worth emphasising that human capital and education have become global factors and that access to them is nowadays unlimited (see Xiaolan et al. 2011, p. 1208).

The flows of information and capital have enhanced the development possibilities of both enterprises and entire economies. Companies create networks of international cooperation, whereas economies are becoming increasingly open. Recent years have brought a growth of enterprises, both in terms of size and scope of activities, by means of streamlining international information flows and their application for market expansion, as well as considerable restriction of trade barriers.

Innovation processes are becoming increasingly international, or even global in nature, which stems from their character and range. Apart from that, the following factors seem crucial (see Kwon and Chun 2015):

- differences in the price of production factors: companies move their production to where production factors are the cheapest;

- necessity for companies to have direct control over the creation of individual elements of innovation;

- level of transactional costs of access to innovation assets;

- emergence of technology gaps.

Taking the above into consideration, it can be said that modern innovation processes are based on the internal potentials of enterprises and their capacity for efficient international technology transfer.

In the long term, technology transfer is the main component of technical progress as it leads to increased productivity and helps to narrow the gap between less and more developed countries. As a result, the return rate from innovative investments is more than twice as large as those in physical capital. What is more, it grows in those branches in which R\&D expenditure is rising. Importantly, more vigorous R\&D efforts and better technology transfer in one economy spread onto other countries involved in international division of labour, providing a boost to their competitiveness (see Chen et al. 2011).

Domestic economies participate in technology flows regardless of their development level and innovative capacities. Trade exchange is associated with their 
technological level, but also makes it possible for companies and states to reach higher levels of advancement thanks to the adoption of new methods of production, organisation, management, creation of new products, or finding new sales outlets. The comparative advantages of highly developed countries depend, therefore, on their involvement in innovative activity: the greater the technological gap, the higher the advantage of benefits from foreign trade (see Daim et al. 2014).

With regard to its creation and diffusion, technological progress is a global phenomenon. It follows that the efficiency with which it is implemented is tantamount to the efficiency of international technology transfer. Enterprises will locate their businesses in those economies which ensure high effectiveness and profitability of undertaken activities. That is why individual countries must develop systems which are perfectly prepared for receiving foreign investments so as to guarantee a positive impact on growth dynamics. Otherwise, the effects of corporate activity might prove to be negative.

It is indispensable for an analysis regarding international technology transfer that an explanation is provided of the means, possibilities and nature of knowledge and technology flows between firms from various countries. However, despite the existence of overall estimations, the scale of the ITT process is difficult to gauge, which causes analytical difficulties. The sensitive nature of this type of transactions reflects the transfer of prices and profits, and is only a part of an entire economic system, which is frequently overlooked.

The basic model of transnational corporations' technological expansion is based on two fundamental assumptions concerning the influence of technology transfer on competitiveness (see Flaherty 1986, pp. 92-94; Takakuwa and Veza 2013):

- technological intensity creates technological advantages on the basis of intangible assets which can be easily transferred within a company, but not outside it;

- by using its own foreign production technology an enterprise can gain a higher rate of return from (technical) investments, which is possible thanks to a wider range of technology sales and receiving extraordinary gains.

The rate of technology transfer will grow if international enterprises increase the flow of "soft" technologies, which will have a positive impact on competitive advantages as far as the use of non-embodied technologies is concerned. The absorption capacities of foreign branches must be reinforced in order to create chances for the development of the obtained technologies. Organisational strategies of companies must shift from the transfer of existing technologies towards the transfer of knowledge and raising of qualifications in order to enhance the potential for research and gain developmental benefits.

Factors which influence the internationalisation of technology transfer vary over time. Statistical data suggest that supply factors are becoming increasingly important, which will lead to limited accessibility of highly qualified R\&D personnel and technical staff. This means a decrease in the significance of demand factors, directly resulting from "globalisation of product flows" and lower capacity to adapt technologically new products to local markets. It is worth mentioning that the innovative activity of large international corporations is concentrated in but a few countries. 
Analysis shows that internationalisation of technology transfer is a necessity. What matters for an enterprise is the possibility to expand this process and not to change its nature. International companies create the foundations for technological development on a global scale, greatly augmenting the developmental potentials of economies, as well as improving their competitive levels through an evolution of high-tech goods markets.

Nowadays (unlike in the 1970s or 1980s), ITT's chief goal is to achieve the highest possible efficiency of participation in global production processes. International affiliations of firms create favourable conditions for increased domestic (local) technological capabilities, better access to new buyers and suppliers, growth of production quality, and finally, higher competitiveness.

\section{Research method}

This research uses the method of soft modelling developed by Wold (1980, 1982). It allows users to examine links between variables which are not directly observable (latent variables). The values of these variables cannot be directly gauged because of the lack of a widely accepted definition or method of their measurement. The soft model consists of two submodels: an internal one (structural model) and an external one (measurement model).

The internal submodel describes dependencies between latent variables implied by the assumed theoretical model. Formally, the internal submodel can be expressed as (see Esposito Vinzi et al. 2010, p. 27)

$$
\Xi_{\mathrm{end}}=\boldsymbol{\Xi}_{\mathrm{end}} \cdot \mathbf{B}+\boldsymbol{\Xi}_{\mathrm{egz}} \cdot \mathbf{C}+\mathbf{V}
$$

where $\mathbf{B}=\left[b_{i j}\right]-n$-square matrix with a diagonal of zeroes, $\mathbf{C}=\left[c_{i j}\right]-$ $((k-n) \times n)$-dimensional matrix of structural parameters associated with endogenous and predetermined variables, respectively, $\mathbf{V}=\left[v_{j}\right]-n$-dimensional vector of random components with expected values equal to zero and finite variances, $\Xi_{\text {end }}=$ $\left[\xi_{1}, \ldots, \xi_{n}\right]-n$-dimensional row vector of unlagged endogenous variables, $\Xi_{\text {egz }}=$ $\left[\xi_{n+1}, \ldots, \xi_{k}\right]-(k-n)$-dimensional row vector of predetermined theoretical variables.

Additionally, it is assumed that the random component of the $j$ th equation $v_{j}$ is not correlated with this equation's explanatory variables $(j=1, \ldots, n)$.

In the external model, latent variables are defined by means of observable variables (indicators). Indicators allow for indirect observation of latent variables and are selected on the basis of a theory or the researcher's intuition. A latent variable can be defined inductively: the approach is based on the assumption that indicators form latent variables (formative indicators), or deductively, based on the premise that indicators reflect their theoretical notions (reflective indicators). In the deductive approach, a latent variable — as a theoretical notion — is a starting point in the search for empirical data. (The variable precedes a given indicator.) In the inductive approach, it is indicators that precede the latent variable which they form. Under both approaches, latent variables are estimated as weighted sums of their indicators. However, depending on 
the definition, indicators should have different statistical properties (lack of correlation in the case of the inductive definition and high correlation in the case of the deductive definition).

The formal notation of external relations is as follows (see Esposito Vinzi et al. 2010, p. 28)

$$
\bigvee_{j=1, \ldots, k} \bigvee_{t=1, \ldots, T} \xi_{t j}=\sum_{i} w_{i j} x_{t i j}
$$

where $\xi_{t j}-t$ th value of variable $\xi_{j}, x_{t i j}-t$ th value of $i$ th indicator of variable $\xi_{j}$, $w_{i j}$-weight associated with $x_{i j}$, when defining $\xi_{j}$.

Therefore, it is assumed that each latent variable is a weighted sum of its indicators. Moreover, for each reflective indicator, the relation measuring the strength of reflection is given

$$
\bigvee_{j=1, \ldots, k} \bigvee_{t=1, \ldots, T} x_{t i j}=\pi_{i j 0}+\pi_{i j} \xi_{t j}+\mu_{t i j}
$$

where $\pi_{i j}$-factor loading measuring the strength of reflection of the latent variable $\xi_{j}$ by its $i$ th indicator, $\mu_{t i j}$-random component with expected values equal to zero.

Moreover, it is assumed that random components are not correlated in time (no autocorrelation) or between equations, or with the latent variables. Additionally, a unit-variance $\xi_{j}$ is also assumed.

The estimation of soft model parameters is performed by means of the partial leastsquares method (see for example, Lohmöller 1989; Esposito Vinzi et al. 2010). The quality of the model is assessed using coefficients of determination $\left(R^{2}\right)$, calculated for each equation. The significance of the parameters is analysed by means of standard deviations, calculated with the help of the Tukey's test (see Jöreskog and Wold 1982). ${ }^{1}$ Besides, in the case of the external model, estimators of factor loadings can be treated as the degree of fit between each indicator and the latent variable which they define. The predictive quality of the model is assessed by means of the Stone-Geisser (S-G) test (see Bergström and Wold 1983), ${ }^{2}$ which measures the accuracy of a prediction performed on the basis of the model in juxtaposition to a trivial prediction. The test statistics take values from the range of $(-\infty, 1\rangle$. For an ideal model, the value of the test equals 1. (Predictions are accurate in comparison with trivial predictions.) If the value is equal to zero, the quality of the model's prediction is, on average, identical to the quality of a trivial prediction. Negative values indicate low quality of the model (worse predictive value of the model in comparison with a trivial predictions).

By applying the partial least-square method, estimates of values of the latent variables are made. They can be treated as values of synthetic measures and can be used to produce a linear ordering of the studied objects. These estimates depend not only on external relationships, but also on the relationships among the latent values assumed

\footnotetext{
1 When examining the significance of parameters, the so-called "2s" rule is used, according to which a parameter significantly differs from zero if double standard deviation does not exceed the value of the estimator.

2 The test was proposed by H. Wold.
} 
in the internal model. This means that the cognitive process is not only dependent on the definition of a given notion, but also on its theoretical description.

\section{Specification of the soft model}

The model used for realisation of the research objective, i.e. proving the influence of international technology transfer on innovation, contains the following equation

$$
\mathrm{INN}_{t}=\alpha_{1} \mathrm{ITT}_{t}+\alpha_{0}+v_{t}
$$

where $\mathrm{INN}_{t}$ - the level of innovation in year $t$, ITT $t$-international technology transfer in year $t, \alpha_{0}, \alpha_{1}$-structural parameters of the model, $v_{t}$-random component, $t$-year 2008 or 2014.

In the model, the deductive approach to defining latent variables is used, i.e. each latent variable as a theoretical notion is a starting point for search for empirical data. The choice of indicators is made on the basis of substantive and statistical criteria. From the statistical perspective, the following properties are taken into account:

- diversity of indicator, measured by the coefficient of variation ${ }^{3}$ - critical value of the coefficient was established at $10 \%$;

- the quality of the estimated model (significance of model parameters, coefficient of determination, $\mathrm{S}-\mathrm{G}$ test).

The statistical data come from the World Bank's and Eurostat's databases. The model's estimations regard two periods: the years 2008 and $2014 .{ }^{4}$ To overcome data shortages, we use naive prediction, consisting in replacing a lacking value with an adjacent one. Two countries, Greece and Great Britain, have been excluded from the research. 5

The indicators which passed substantive and statistical verification are presented in Table 1. All the indicators of latent variables $\mathrm{ITT}_{t}$ and $\mathrm{INN}_{t}$ are stimulants, i.e. higher values of such indicators mean higher levels of variables. The $\mathrm{ITT}_{t}$ indicators point to the most frequent and significant international transfer technology channels. Meanwhile, the INN $\mathrm{IN}_{t}$ measures reflect the capacity for creating and diffusing innovations (Schumpeterian triad).

A schematic diagram of the soft model, taking into consideration both the internal and external relationships, is presented in Fig. 1. ${ }^{6}$ The model was estimated using the partial least-squares method, which enables simultaneous estimation of the external model parameters (weights and factor loadings) and the internal model parameters (structural parameters). The estimation was conducted with the help of PLS software. ${ }^{7}$

\footnotetext{
3 Calculated as ratio of standard deviation to arithmetic mean, expressed in percents.

4 Selection was determined by the availability of statistical data.

5 The exclusion was due to a high percentage of lacking data for these countries.

6 The solid line represents internal model relationships, while the broken line-external model relationships.

7 The software was developed by Prof. J. Rogowski from the Faculty of Economics and Management, University of Biaystok and is free of charge.
} 
Table 1 Indicators of latent variables $\mathrm{ITT}_{t}$ and $\mathrm{INN}_{t}$ qualified for the model

\begin{tabular}{|c|c|c|}
\hline Symbol of indicator & Description of indicator & Data source \\
\hline ITT1 & Foreign direct investment, net (\% of GDP) & World Bank \\
\hline ITT2 & High-tech import (\% of total) & Eurostat \\
\hline ITT3 & $\begin{array}{l}\text { Product and/or process innovative enterprises, engaged } \\
\text { in any type of innovation cooperation with a partner in } \\
\text { EU countries, EFTA or EU candidates countries ( } \% \text { of } \\
\text { total) }\end{array}$ & Eurostat \\
\hline ITT4 & $\begin{array}{l}\text { Product and/or process innovative enterprises, engaged } \\
\text { in any type of innovation cooperation with a partner in } \\
\text { USA (\% of total) }\end{array}$ & Eurostat \\
\hline ITT5 & $\begin{array}{l}\text { Product and/or process innovative enterprises, engaged } \\
\text { in any type of innovation cooperation with a partner in } \\
\text { China or India (\% of total) }\end{array}$ & Eurostat \\
\hline INN1 & Total intramural R\&D expenditure (\% of GDP) & Eurostat \\
\hline INN2 & Business enterprise R\&D expenditure (\% of GDP) & Eurostat \\
\hline INN3 & High-tech export (\% of total) & Eurostat \\
\hline INN4 & $\begin{array}{l}\text { Employment in knowledge-intensive activities (\% of } \\
\text { total employment) }\end{array}$ & Eurostat \\
\hline INN5 & $\begin{array}{l}\text { Patent applications to the EPO (per } 1 \text { million } \\
\text { inhabitants) }\end{array}$ & Eurostat \\
\hline INN6 & Innovative enterprises ( $\%$ of total) & Eurostat \\
\hline INN7 & Total turnover of innovative enterprises ( $\%$ of GDP) & Eurostat \\
\hline
\end{tabular}

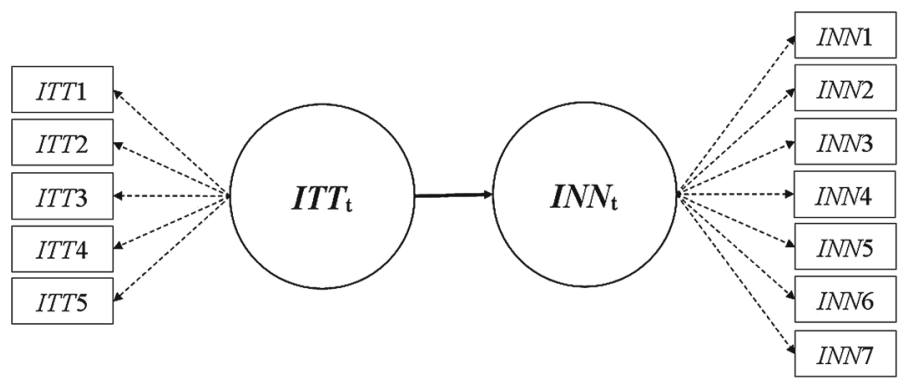

Fig. 1 Schematic diagram of internal and external relationships of the soft model

\section{Soft model estimation results: 2008}

The results of the estimation of the external model are presented in Table 2. Each weight represents the relative share of a given indicator's value in the estimated value of a latent variable. Factor loadings are coefficients of correlation between indicators and latent variables, thus indicating the degree and direction in which the variability of an indicator reflects the variability of a latent variable. The ordering of indicators according to weight is performed when a latent variable is defined inductively. In the deductive approach, which was applied in this research, it is the factor loadings that are interpreted. The following interpretation of the $\pi_{i j}$ factor loading is assumed: 
Table 2 Estimations of external relationships parameters in the soft model, year 2008

\begin{tabular}{lllll}
\hline Symbol of indicator & Weight & SD & Factor loading & SD \\
\hline ITT1 & 0.3173 & 0.0113 & 0.7481 & 0.0156 \\
ITT2 & 0.2759 & 0.0224 & 0.6062 & 0.0241 \\
ITT3 & 0.1517 & 0.0142 & 0.6246 & 0.0188 \\
ITT4 & 0.3172 & 0.0097 & 0.8589 & 0.0137 \\
ITT5 & 0.2845 & 0.0097 & 0.8020 & 0.0154 \\
INN1 & 0.1704 & 0.0265 & 0.7908 & 0.0531 \\
INN2 & 0.1901 & 0.0161 & 0.8346 & 0.0299 \\
INN3 & 0.2036 & 0.0333 & 0.5956 & 0.0824 \\
INN4 & 0.2670 & 0.0441 & 0.8816 & 0.0826 \\
INN5 & 0.1958 & 0.0373 & 0.8693 & 0.0677 \\
INN6 & 0.1237 & 0.0469 & 0.7236 & 0.1131 \\
INN7 & 0.1540 & 0.0753 & 0.5752 & 0.1185 \\
\hline
\end{tabular}

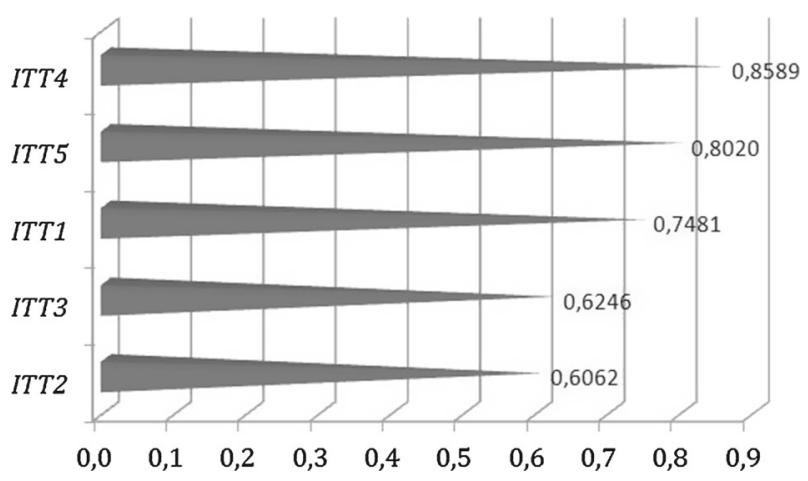

Fig. 2 Estimations of factor loadings of $\mathrm{ITT}_{2008}$ latent variable

$-\left|\pi_{i j}\right|<0.2$ - no correlation,

$-0.2 \leq\left|\pi_{i j}\right|<0.4$-weak correlation,

$-0.4 \leq\left|\pi_{i j}\right|<0.7$-moderate correlation,

$-0.7 \leq\left|\pi_{i j}\right|<0.9$ - strong correlation,

$-\left|\pi_{i j}\right| \geq 0.9$ - very strong correlation.

In terms of the signs of the estimated parameters, the results are consistent with the expectations. Being stimulants, all the indicators have positive estimations of weights and factor loadings. Moreover, all the parameters are statistically significant, in accordance with the " $2 \mathrm{~s}$ " rule.

The indicators reflect their latent variables with varying strength (see Figs. 2, 3).

Three indicators of ITT $_{2008}$ reveal a strong correlation with variable: "Product and/or process innovative enterprises, engaged in any type of innovation cooperation with a partner in USA" (ITT4), "Product and/or process innovative enterprises, engaged in any type of innovation cooperation with a partner in China or India" (ITT5), and 


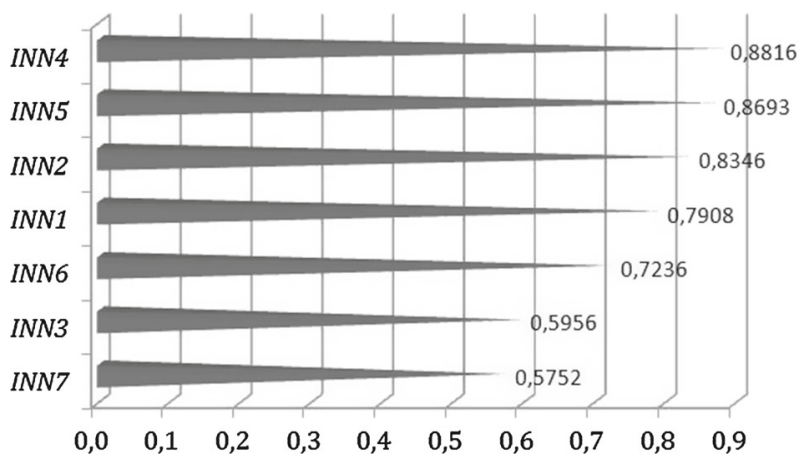

Fig. 3 Estimations of factor loadings of $\mathrm{INN}_{2008}$ latent variable

"Foreign direct investment, net" (ITT1). The variable is moderately correlated with the other two indicators: "Product and/or process innovative enterprises, engaged in any type of innovation cooperation with a partner in EU countries, EFTA or EU candidates countries" (ITT3) and "High-tech import" (ITT2).

Enterprises buy ready-made knowledge or other solutions much more frequently than they engage in $R \& D$ activity or external cooperation for innovation. This is directly due to the cost of these processes. Purchasing cut-and -dried solutions is cheaper and less risky.

The latent variable INN $\mathrm{N}_{2008}$ is strongly reflected by five indicators: "Employment in knowledge-intensive activities" (INN4), "Patent applications to the EPO" (INN5), "Business enterprise R\&D expenditure" (INN2), "Total intramural R\&D expenditure" (INN1), and "Innovative enterprises" (INN6). Two indicators: "High-tech export" (INN3) and "Total turnover of innovative enterprises"(INN7) are moderately correlated with the variable.

Enterprises increasingly tend to use patent protection as an effect of the incurred costs of R\&D and as a necessity to secure the results of their intramural research.

The outcomes of the internal model estimation are illustrated by the following equation. The brackets contain standard deviations calculated by means of the Tukey's test.

$$
\widehat{\mathrm{INN}}_{2008}=\underset{(0.0317)}{0.8127} \cdot \mathrm{ITT}_{2008}+\underset{(0.2072)}{1.5388} R^{2}=0.66
$$

The structural parameters are statistically significant. The value of the coefficient of determination justifies the conclusion that, to a moderate extent, the explanatory variable $\mathrm{ITT}_{2008}$ determines the variability of the explained variable $\mathrm{INN}_{2008}$. The values of the Stone-Geisser test statistic, which verifies the soft model in terms of its predictive usefulness (see Table 3), are positive, which proves the model's high predictive quality.

The estimation of the internal model parameters indicates a positive significant correlation between international technology transfer and the level of innovation in the studied group of 26 European Union countries in 2008. This means that those 
Table 3 Stone-Geisser test results, year 2008

\begin{tabular}{ll}
\hline Symbol of indicator & Value of S-G test statistic \\
\hline INN1 & 0.2526 \\
INN2 & 0.3287 \\
INN3 & 0.3192 \\
INN4 & 0.4798 \\
INN5 & 0.3562 \\
INN6 & 0.0951 \\
INN7 & 0.0061 \\
General & 0.3564 \\
\hline
\end{tabular}

countries in which reported more intensive transfer of technology were also more innovative in that year.

Many enterprises treat ITT as a vital source of technological solutions, used later to create their own innovations.

International technology transfer is a multilateral flow of information and technical knowledge. It integrates various scientific fields, institutions, and business entities. Knowledge thus obtained contributes to the creation of a certain, more or less advanced, technological base. At the same time, this base plays an important part in the process of technology transfer. Business companies usually strive to implement the technologies they buy, and thus, new technologies improve production efficiency. Effective management of technologies generates technological innovations along with organisational systems and new sources for financing innovation. This can be noticed when one examines the rankings of economies.

By analysing the results, we can assess the ITT processes and their impact on the innovation levels of the studied countries. There is an evident diversity of this type of relationships, particularly in terms of innovation. This is mainly due to the effectiveness of the ITT process itself, and on the other hand due to the degree of particular countries' readiness to adopt and utilise technologies.

The transformation of the ITT-based EU economies manifested itself primarily in changes regarding the structure of the markets (larger share of high-tech industries), macroeconomic stabilisation, and institutional changes. Liberalisation of economic systems and improved conditions for free market competition increased the emphasis on the efficiency of enterprises, their greater competitiveness, and the changes in their functioning within the domestic innovation systems. Economies became more open to economic ties with foreign countries, which to a large extent were a source of technology transfer.

New market institutions provided a boost to business efficiency and dynamised economic development. This, undoubtedly, stimulated innovativeness, mainly thanks to increased ability to assess market needs. Apart from examining the correlations between latent variables, soft modelling also helps estimate the values of these variables (weighted sums of indicators). Therefore, for each of the latent variable in the model a synthetic measurement is calculated, which can be used to obtain a linear ordering of the analysed objects. 
Table 4 Rankings of international technology transfer and innovation in EU countries in 2008

\begin{tabular}{|c|c|c|}
\hline Country & $\mathrm{ITT}_{2008}$ & $\mathrm{INN}_{2008}$ \\
\hline Austria & 14 & 6 \\
\hline Belgium & 4 & 9 \\
\hline Bulgaria & 26 & 24 \\
\hline Croatia & 21 & 20 \\
\hline Cyprus & 12 & 16 \\
\hline Czech Republic & 15 & 13 \\
\hline Denmark & 5 & 5 \\
\hline Estonia & 17 & 17 \\
\hline Finland & 2 & 4 \\
\hline France & 10 & 7 \\
\hline Germany & 19 & 3 \\
\hline Hungary & 11 & 14 \\
\hline Ireland & 9 & 8 \\
\hline Italy & 22 & 15 \\
\hline Latvia & 25 & 25 \\
\hline Lithuania & 18 & 22 \\
\hline Luxembourg & 1 & 1 \\
\hline Malta & 7 & 11 \\
\hline Netherlands & 6 & 10 \\
\hline Poland & 16 & 23 \\
\hline Portugal & 20 & 18 \\
\hline Romania & 24 & 26 \\
\hline Slovakia & 13 & 21 \\
\hline Slovenia & 8 & 12 \\
\hline Spain & 23 & 19 \\
\hline Sweden & 3 & 2 \\
\hline
\end{tabular}

Basing on the synthetic measurements of the variables ITT $_{2008}$ and $\mathrm{INN}_{2008}$, two rankings of the studied countries have been compiled: a ranking of international technology transfer and a ranking of innovation. The results are shown in Table 4.

The countries are also divided into typological groups according to similar volumes of international technology transfer (and thus similar innovation levels). The results of the grouping are presented in Figs. 4 and 5. The boundaries between the groups have been established on the basis of the arithmetic means and standard deviations of the synthetic measure $z_{i}$ (equal to 0 and 1 , respectively, for each of the latent variables). The groups are as follows:

- group I. (very high level of latent variable): $z_{i} \geq 1$,

- group II. (high level of latent variable): $0<z_{i} \leq 1$,

- group III. (medium and low level of latent variable): $-1<z_{i} \leq 0$,

- group IV. (very low level of latent variable): $z_{i} \leq-1$. 


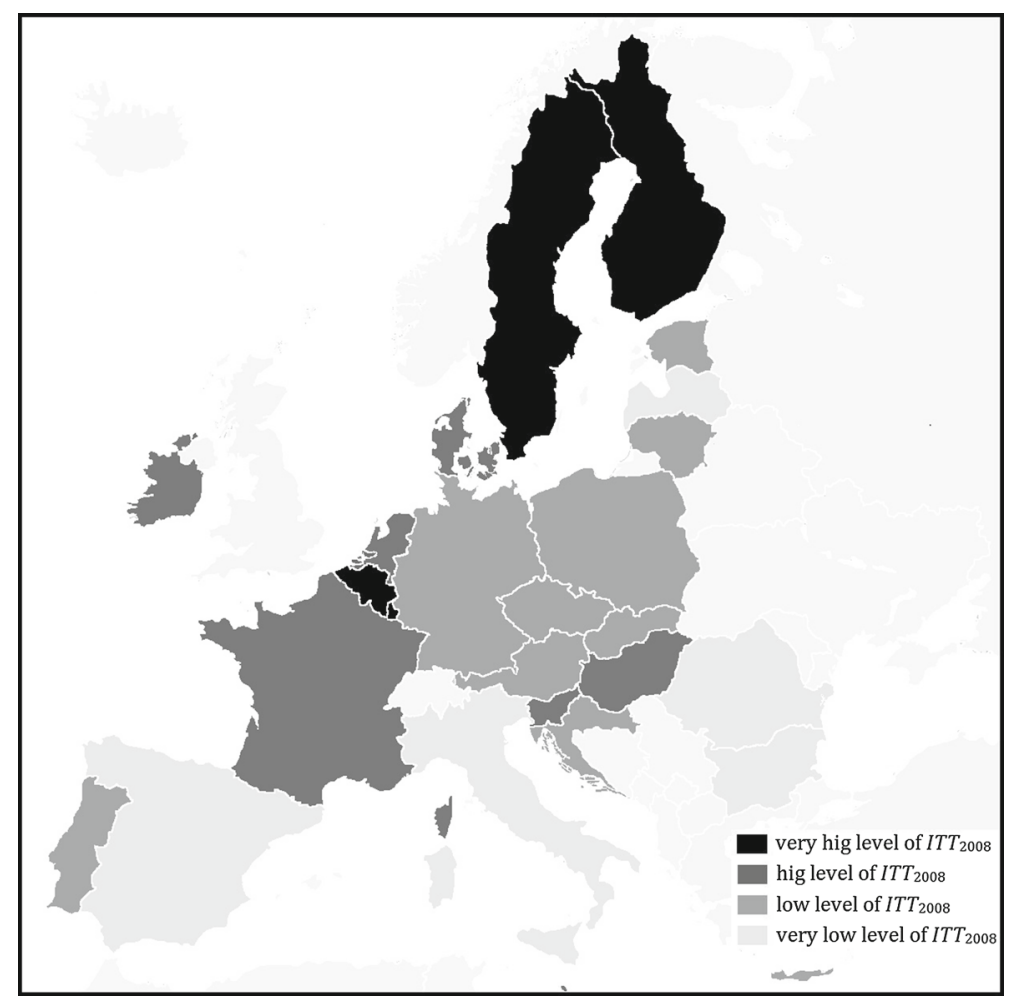

Fig. 4 Division of EU countries into typological groups according to international technology transfer in 2008

Very high international technology transfer was observed in 2008 in the following countries: Luxemburg, Finland, Sweden, and Belgium. The group with high international technology transfer comprised seven countries: Denmark, Netherlands, Malta, Ireland, France, Slovenia, and Hungary. Ten countries were qualified for the group of economies with medium and low levels of international technology transfer: Germany, Austria, Cyprus, Slovakia, Czech Republic, Estonia, Portugal, Croatia, Poland, and Lithuania. Five countries were characterised by very low levels of international technology transfer: Italy, Spain, Romania, Latvia, and Bulgaria.

The ranking of countries according to ITT demonstrates a dominance of relatively small economies relying on the service sector (Luxembourg, Netherlands) and those "catch-up" economies (Estonia, Ireland) which take advantage of the inflow of technologies from large foreign corporations. The lower ranks are occupied by economies with high shares of low-tech industries (Italy, Spain) and "catch-up" economies (Romania, Bulgaria) at low levels of economic development.

Four countries were qualified for the group of economies at very high innovation levels in 2008: Luxemburg, Finland, Sweden, and Germany. The group of highly innovative economies comprises: Belgium, Denmark, Netherlands, Malta, Ireland, France, and Austria. Group III-countries at medium and low innovation levels- 


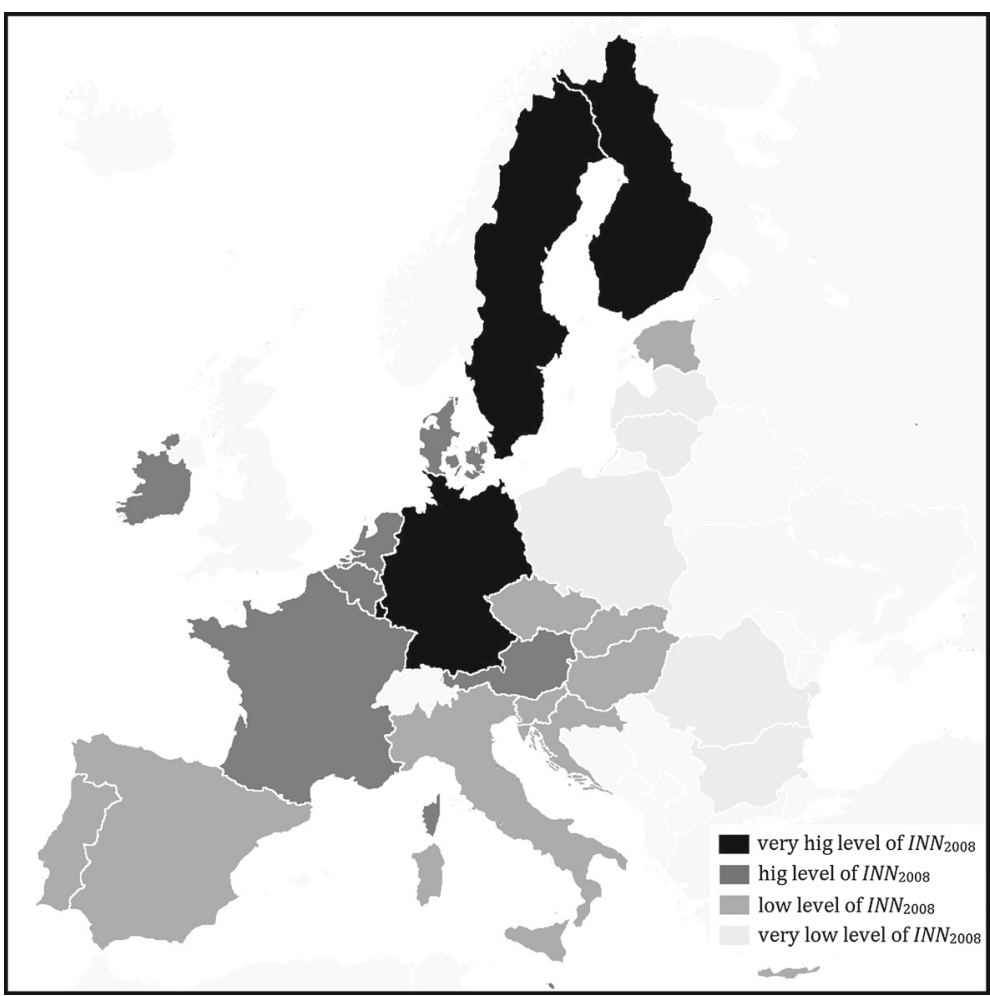

Fig. 5 Division of EU countries into typological groups according to innovation level in 2008

consists of: Slovenia, Hungary, Cyprus, Slovakia, Czech Republic, Estonia, Portugal, Croatia, Italy, and Spain. Low levels of innovation were reported by Poland, Lithuania, Romania, Latvia, and Bulgaria.

However, when one takes into account the benefits from ITT in the form of higher innovation, the classification looks different. Here, the top ranks are occupied by economies with internal abilities to adopt and create innovation, ones based on the R\&D sector (Germany, Sweden, Austria), whereas countries with weak R\&D sectors and poor ability to create their own technological solutions, (Romania, Bulgaria, Latvia, Poland) are ranked at the bottom.

\section{Soft model estimation results: 2014}

Table 5 shows the results of the estimation of the external model. Positive values of all the estimated weights and factor loadings are consistent with the expectations. The parameters are statistically significant, in accordance with the " $2 \mathrm{~s}$ " rule. Figures 6 and 7 present the strength of reflecting latent variable by their indicators.

The latent variable ITT $_{2014}$ is very strongly reflected by the indicator "Product and/or process innovative enterprises, engaged in any type of innovation cooperation 
Table 5 Estimations of external relationships parameters in the soft model, year 2014

\begin{tabular}{lllll}
\hline Symbol of indicator & Weight & SD & Factor loading & SD \\
\hline ITT1 & 0.1861 & 0.0573 & 0.3045 & 0.0555 \\
ITT2 & 0.3235 & 0.0593 & 0.5585 & 0.0534 \\
ITT3 & 0.1066 & 0.0259 & 0.6457 & 0.0339 \\
ITT4 & 0.4348 & 0.0068 & 0.9284 & 0.0137 \\
ITT5 & 0.3275 & 0.0170 & 0.8859 & 0.0236 \\
INN1 & 0.2101 & 0.0212 & 0.8367 & 0.0707 \\
INN2 & 0.2006 & 0.0295 & 0.8312 & 0.0560 \\
INN3 & 0.1900 & 0.0588 & 0.5104 & 0.0828 \\
INN4 & 0.2349 & 0.0690 & 0.7558 & 0.0553 \\
INN5 & 0.2096 & 0.0559 & 0.8267 & 0.0483 \\
INN6 & 0.1396 & 0.0395 & 0.8361 & 0.0833 \\
INN7 & 0.1441 & 0.1094 & 0.6445 & 0.0775 \\
\hline
\end{tabular}

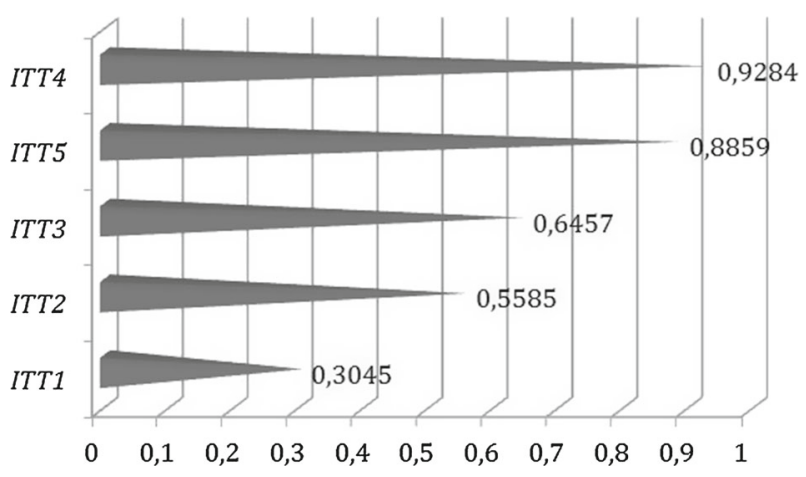

Fig. 6 Estimations of factor loadings of $\mathrm{ITT}_{2014}$ latent variable

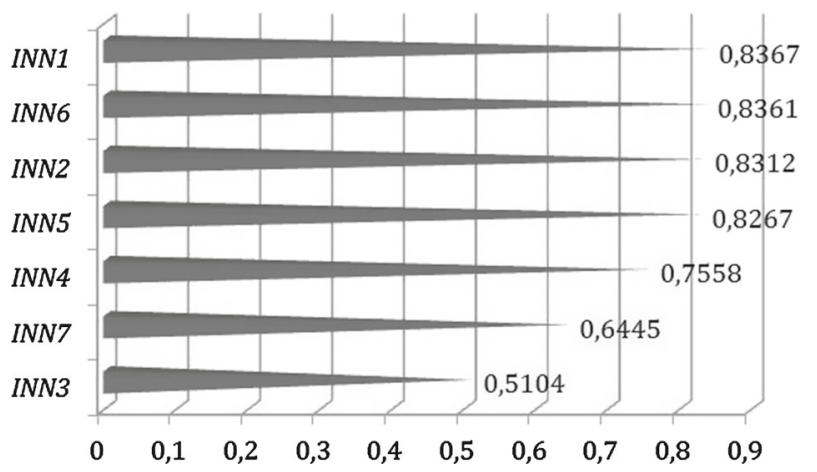

Fig. 7 Estimations of factor loadings of $\mathrm{INN}_{2014}$ latent variable 
Table 6 Stone-Geisser test results, year 2014

\begin{tabular}{ll}
\hline Symbol of indicator & Value of S-G test statistic \\
\hline INN1 & 0.1510 \\
INN2 & 0.1833 \\
INN3 & 0.1385 \\
INN4 & 0.1939 \\
INN5 & 0.1851 \\
INN6 & 0.0492 \\
INN7 & 0.0657 \\
General & 0.1823
\end{tabular}

with a partner in USA" (ITT4), while the indicator Product and/or process innovative enterprises, engaged in any type of innovation cooperation with a partner in China or India (ITT5) is strongly correlated with it. The variable is moderately correlated with two indicators: "Product and/or process innovative enterprises, engaged in any type of innovation cooperation with a partner in EU countries, EFTA or EU candidates countries" (ITT3) and "High-tech import" (ITT2). The indicators: "Foreign direct investment, net" (ITT1) weakly reflects the latent variable ITT $_{2014}$.

The estimation results reveal a significant weakening of the impact of ITT1 on the latent variable $\mathrm{ITT}_{t}$. In the model constructed for data from 2008, this impact was strong, whereas here it is weak. The differences between the two sets of modelling results are also visible in the strength of the influence of the ITT4 indicator (strong impact in 2008, very strong impact in 2014).

The latent variable INN 2014 is strongly reflected by five indicators: "Total intramural R\&D expenditure" (INN1), "Innovative enterprises" (INN6), "Business enterprise R\&D expenditure" (INN2), "Patent applications to the EPO" (INN5), and "Employment in knowledge-intensive activities" (INN4). Two indicators, "Total turnover of innovative enterprises" (INN7) and "High-tech export" (INN3), are moderately correlated with the variable.

The results show a clearly diminished role of FDI in technology transfer. More and more often, transfer is internal in its character and is implemented by enterprises and institutions in the country of origin. This can also be noticed in indicators reflecting the levels of R\&D expenditure.

The following equation describes the estimations of internal model parameters along with standard deviations given in brackets

$$
\widehat{\mathrm{INN}}_{2014}=\underset{(0.0222)}{0.6277} \cdot \mathrm{ITT}_{2014}+\underset{(0.3528)}{1.8036} R^{2}=0.39
$$

The structural parameters of the model are statistically significant. The value of the coefficient of determination is fairly low and indicates that the explanatory variable ITT $_{2014}$ determines the variability of the explained variable $\mathrm{INN}_{2014}$ only to a limited extent. The values of the Stone-Geisser test statistic (see Table 6) are positive, which proves that the model's predictive quality is high. 
Table 7 Rankings of international technology transfer and innovation in EU countries in 2014

\begin{tabular}{|c|c|c|c|c|}
\hline Country & $\mathrm{ITT}_{2014}$ & Change & $\mathrm{INN}_{2014}$ & Change \\
\hline Austria & 10 & $\downarrow$ & 4 & $\uparrow$ \\
\hline Belgium & 8 & $\downarrow$ & 6 & $\uparrow$ \\
\hline Bulgaria & 23 & $\uparrow$ & 25 & $\downarrow$ \\
\hline Croatia & 20 & $\uparrow$ & 22 & $\downarrow$ \\
\hline Cyprus & 15 & $\downarrow$ & 16 & $\uparrow$ \\
\hline Czech Republic & 12 & $\uparrow$ & 12 & $\uparrow$ \\
\hline Denmark & 3 & $\uparrow$ & 9 & $\downarrow$ \\
\hline Estonia & 6 & $\uparrow \uparrow \uparrow$ & 17 & $\uparrow$ \\
\hline Finland & 7 & $\downarrow \downarrow$ & 5 & $\downarrow$ \\
\hline France & 13 & $\downarrow$ & 8 & $\downarrow$ \\
\hline Germany & 18 & $\uparrow$ & 2 & $\uparrow$ \\
\hline Hungary & 14 & $\downarrow$ & 14 & $\uparrow$ \\
\hline Ireland & 1 & $\uparrow \uparrow$ & 7 & $\uparrow$ \\
\hline Italy & 26 & $\downarrow$ & 15 & $\uparrow$ \\
\hline Latvia & 16 & $\uparrow \uparrow$ & 24 & $\downarrow$ \\
\hline Lithuania & 21 & $\downarrow$ & 20 & $\uparrow$ \\
\hline Luxembourg & 5 & $\downarrow$ & 3 & $\downarrow$ \\
\hline Malta & 19 & $\downarrow \downarrow \downarrow$ & 13 & $\downarrow$ \\
\hline Netherlands & 9 & $\downarrow$ & 10 & $\uparrow$ \\
\hline Poland & 17 & $\downarrow$ & 23 & $\uparrow$ \\
\hline Portugal & 25 & $\downarrow \downarrow$ & 18 & $\uparrow$ \\
\hline Romania & 24 & $\uparrow$ & 26 & $\uparrow$ \\
\hline Slovakia & 4 & $\uparrow \uparrow$ & 21 & $\uparrow$ \\
\hline Slovenia & 11 & $\downarrow$ & 11 & $\uparrow$ \\
\hline Spain & 22 & $\uparrow$ & 19 & $\uparrow$ \\
\hline Sweden & 2 & $\uparrow$ & 1 & $\uparrow$ \\
\hline
\end{tabular}

Equation 6 indicates a positive, significant correlation between international technology transfer and the level of innovation in the studied group of $26 \mathrm{EU}$ countries in 2014. This means that countries which in 2014 recorded more intensive technology transfer were also more innovative in that year. The strength of the correlation is lower as compared with the year 2008.

ITT turns out to be a key factor of innovation growth in the entire studied group. The differences concern only its structure: transfer occurs via other channels and is embodied in different forms.

Table 7 presents the analysed countries ranked according to their volume of international technology transfer as well as their innovation in 2014. Figures 8 and 9 show the results of grouping EU countries.

When comparing the above rankings with those obtained on the basis of 2008 data, one notices considerable changes in the ordering of the countries in terms of 


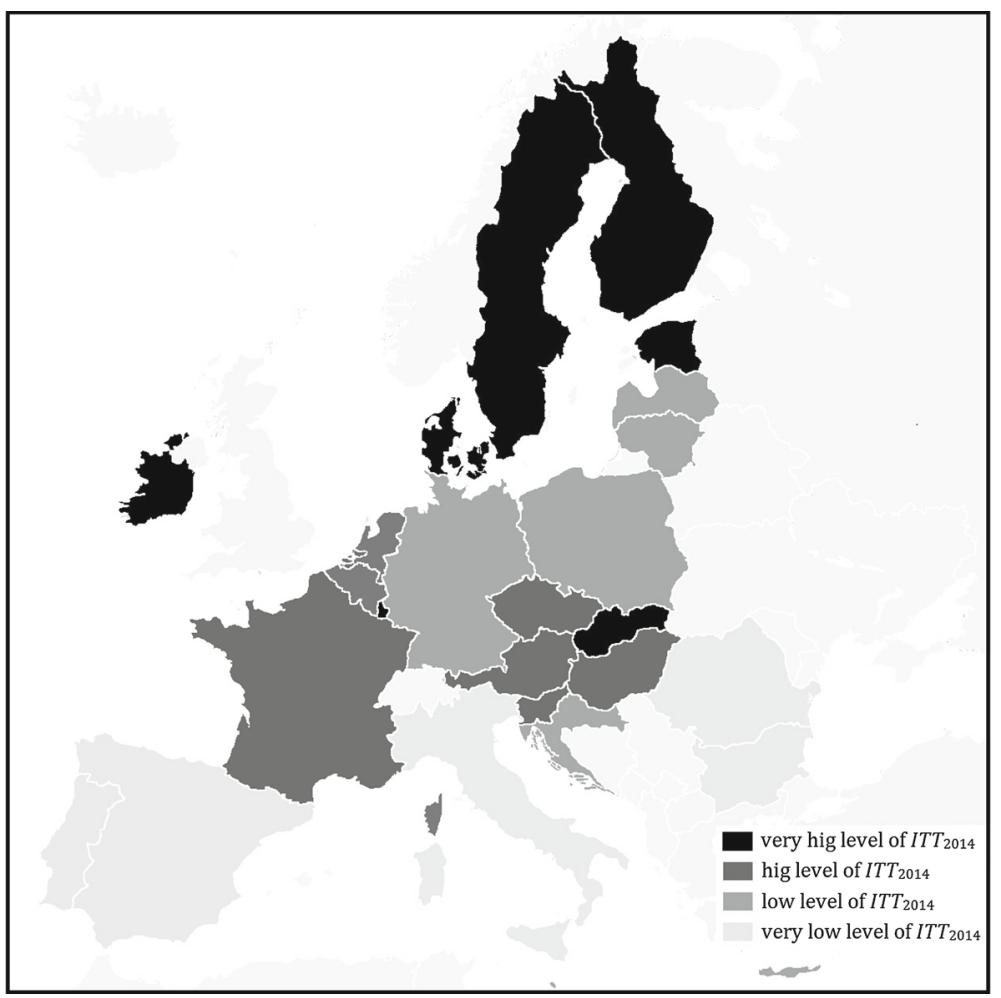

Fig. 8 Division of EU countries into typological groups according to international technology transfer in 2014

international technology transfer and relatively small changes in the innovation ranking (see columns 2 and 4 in Table 7). The following countries moved up spectacularly in the ITT rankings: Estonia (17th in 2008, 6th in 2014), Ireland (9th in 2008, 1st in 2014), Latvia (25th in 2008, 16th in 2014), and Slovakia (13th in 2008, 4th in 2014). Three countries recorded significant drops: Malta (7th in 2008, 19th in 2014), Finland (2nd in 2008, 7th in 2014), and Portugal (20th in 2008, 25th in 2014).

The improvement of the technological situation in these countries occurred thanks to increasingly greater openness of the economies and a liberalisation of their economic policies. Moreover, it was a result of substantial support given to some high-tech branches (mainly ICT) by the countries' state sectors.

A comparative analysis of the groupings in terms of international technology transfer in the years 2008 and 2014 reveals that the group of leaders in ITT became significantly larger (in 2008 it comprised four countries, while in 2014-seven). Besides, the ranks of ten countries changed: seven of them moved to higher typological groups (Ireland, Denmark, Slovakia, Estonia, Austria, Czech Republic, and Latvia), while three moved down (Belgium, Malta, and Portugal). 


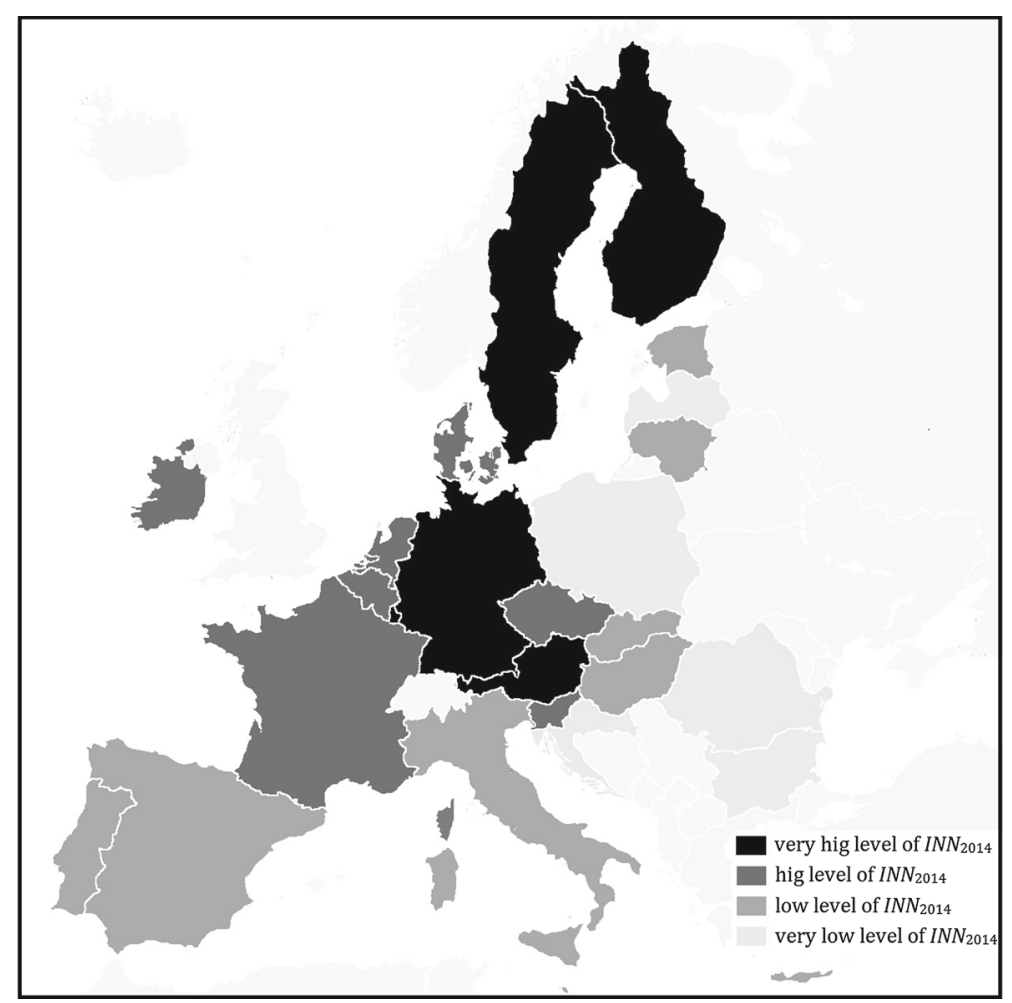

Fig. 9 Division of EU countries into typological groups according to innovation level in 2014

As for the classification in terms of innovativeness, six countries changed ranks: four were classified in higher groups (Austria, Slovenia, Czech Republic, and Lithuania), while two dropped down (Malta and Croatia).

This suggests that the use of ITT in innovative development is becoming increasingly widespread. Those economies which take greater advantage of the effects of technology transfer seem to be far more successful in raising their innovation levels. What is also important, the nature of ITT is changing as well: we observe a shift from "hard" technical solutions towards knowledge.

\section{Conclusions}

The paper examines the relationships between international technology transfer and innovative changes in EU countries. The results of the study showed that there was a very strong, positive correlation between ITT and the innovation level of European economies in recent years. Moreover, the outcomes of the research have enabled to identify the key drivers of ITT and innovation. In the case of ITT, it was cooperation with a partner in the USA, China, or India, while in case of innovation: patents, employment in knowledge-intensive activities, as well as business enterprises R\&D expenditures. 
In the current macroeconomic circumstances, ITT should be regarded as an element of multilateral flow of information and technical knowledge. It integrates various fields of science, institutions, and enterprises, leading to the establishment of a certain more or less advanced technological base. This is tremendously important given the significance of this base for the effectiveness of the transfer. In countries whose technological bases are underdeveloped, economic entities can improve the efficiency of production by implementing technologies acquired elsewhere, or by attempting to create their own solutions in those economies which are technologically robust. The scope of the technological base which is thus constructed determines, therefore, the efficiency of technology management and the possibility to create technological innovations, along with organisation systems and new sources for financing innovative activity.

By analysing the technological rankings of particular countries, we can assess ITT processes and their impact on the levels of innovation. There is a wide variety of this kind of relationships, particularly as regards innovation. This is mainly due to the effectiveness of ITT itself, and on the other hand due to the varying degrees of readiness to absorb and exploit technologies in different countries.

The transformation of EU economies driven by ITT was reflected above all in changes regarding the structure of markets (greater share of high-tech industries and services), macroeconomic stabilisation, and institutional changes. That entailed stronger emphasis on the efficiency of enterprises, their greater competitiveness, and altered role within national innovation systems. Economies became more open to establishing business links with countries which were major sources of technology transfer.

New market institutions operating under innovation systems, mainly thanks to better capability of assessing market needs, have contributed to increase in the efficiency and dynamics of economic development. Without a doubt, this has provided an impetus to innovativeness.

Open Access This article is distributed under the terms of the Creative Commons Attribution 4.0 International License (http://creativecommons.org/licenses/by/4.0/), which permits unrestricted use, distribution, and reproduction in any medium, provided you give appropriate credit to the original author(s) and the source, provide a link to the Creative Commons license, and indicate if changes were made.

\section{References}

Audretsch DB, Lehmann EE, Link AN, Starnecker A (eds) (2012) Technology transfer in a global economy. Springer, Berlin

Belderbos R, Van Roy V, Duvivier F (2013) International and domestic technology transfers and productivity growth: firm level evidence. Ind Corp Change 22(1):1-32. https://doi.org/10.1093/icc/dts012

Bergström R, Wold H (eds) (1983) Fix-point estimation in theory and practise. Vandenhoeck \& Ruprecht, Gottingen

Chen YY, Farris G, Chen YH (2011) Effects of technology cycles on strategic alliances. Int J Technol Manag 54(2-4):121-148. https://doi.org/10.1504/IJTM.2011.038587

Daim T, Neshati R, Watt R, Eastham J (2014) Technology development. Washington University, St. Louis

De La Tour A, Glachant M, Ménière Y (2011) Innovation and international technology transfer: the case of the Chinese photovoltaic industry. Energy Policy 39(2):761-770. https://doi.org/10.1016/j.enpol. 2010.10.050 
Esposito Vinzi V, Chin WW, Henseler K, Wand H (eds) (2010) Handbook of partial least squares: concepts, methods and applications. Springer, Berlin

Flaherty MT (1986) Coordinating international manufacturing and technology. In: Porter ME (ed) Competition in global industries. Boston Harvard Business School Press, Boston, pp 83-110

Gu S, Steinmueller E (1996) Chinas national innovation system approach to participation in information technology: the innovation recombination of technology capability. INTECH Maastricht, Maastricht

Hobday M (1995) Innovation in East Asia: the challenge to Japan. Edward Elgar Publishing, Cheltenham

Jöreskog KG, Wold H (eds) (1982) Systems under indirect observation: causality, structure, prediction. North-Holland, Amsterdam

Kwon CW, Chun BG (2015) The effect of strategic technology adoptions by local firms on technology spillover. Econ Model 51(C):13-20. https://doi.org/10.1016/j.econmod.2015.07.013

Lohmöller JB (1989) Latent variable path modeling with partial least squares. Springer, Berlin

Maskus KE (2004) Encouraging international technology transfer. UNCTAD-ICTSD Issue Paper No. 7. https://unctad.org/en/PublicationsLibrary/ictsd2004ipd7_en.pdf. Accessed 26 June 2017

Ozawa T (1992) Foreign direct investment and economic development. Transnatl Corp 6:27-54

Radosevic S (1999) International technology transfer and catch-up in economic development. Edward Elgar Publishing, Cheltenham

Saggi K (2002) Trade, foreign direct investment, and international technology transfer: a survey. World Bank Res Obs 17(2):191-235. https://doi.org/10.1093/wbro/17.2.191

Stark D (1996) Recombinant property in Eastern European capitalism. Am J Sociol 101(4):993-1027

Takakuwa S, Veza I (2013) Technology transfer and world competitiveness. Proc Eng 69:121-127. https:// doi.org/10.1016/j.proeng.2014.02.211

Wold H (1980) Soft modelling: intermediate between traditional model building and data analysis. Math Stat 6:333-346

Wold H (1982) Soft modeling: the basic design and some extensions. In: Joreskog KG, Wold H (eds) Systems under indirect observation: causality, structure, prediction. Boston Harvard Business School Press, Boston, pp 1-54

Xiaolan F, Pietrobelli C, Soete L (2011) The role of foreign technology and indigenous innovation in the emerging economies: technological change and catching-up. World Dev 39(8):1024-1212

Publisher's Note Springer Nature remains neutral with regard to jurisdictional claims in published maps and institutional affiliations. 